\title{
EL USO DE LA PALABRA MISIÓN EN EL LENGUAJE DE LA PRENSA FEMENINA ESPAÑOLA (1939-1945)
}

Pilar de Vega

$U N E D$

Las relaciones que se establecen entre los signos lingüísticos y los hechos extralingüísticos dentro de una comunidad lingüística determinada y durante una época delimitada, proporcionan una serie de datos fundamentales sobre la utilización del lenguaje, tanto en función del referente que es objeto del mensaje como de la actitud del emisor ante ese referente. Por esta razón, hemos elegido para este estudio una época de cambio sociopolítico, caracterizada por la producción de un lenguaje de tipo ideológico-propagandístico y que presenta gran homogeneidad en la consideración de la mayoría de los temas', pero muy especialmente en la de aquellos que, según las directrices del nuevo estado, deben ser reorganizados ${ }^{2}$.

1 Estas características permiten considerar este tipo de discurso como un lenguaje sectorial, teniendo en cuenta que "el bloque más amplio de los lenguajes sectoriales [lo constituye] el lenguaje de determinadas áreas que son individualizadas tanto por criterios sociológicos $(\ldots)$, como en función del objeto designado $(\ldots)$. como también $(\ldots)$ en virtud del "medio", principalmente los mass-media: prensa, radio y televisión; siempre que tales peculiaridades, en función de los "sujetos", "objetos" o "medios", se reflejen en los Usos del lenguaje". (Bonifacio Rodríguez Díez: Las Lenguas Especiales. El léxico del ciclismo, León, Colegio Universitario de León. 1981, pág. 115.

2 Es indudable que la Prensa, directamente controlada por el Estado, sirve de vehículo para difundir un sistema de valores que se intenta inculcar en el lector mediante una información censurada, e incluso mediante la frecuente inserción de consignas propagandísticas en el texto de las revistas dedicadas a la mujer. Sobre este tema, véase: Javier Terrón Montero: La prensa de España durante el régimen de Franco, Madrid. Centro de Investigaciones Sociológicas, 198I, especialmente, págs. 15-79. Miguel Delibes: La censura de prensa en los años 40, Valladolid. Ambito editorial, 1985. 
El trabajo de la mujer, que durante los primeros años de la posguerra española constituye un problema social de envergadura, ocupa un lugar privilegiado en la prensa que durante esta época se dedica a la mujer ${ }^{3}$. La situación de cambio institucional que se produce influye de manera decisiva en la consideración sobre el papel de la mujer en la sociedad, y este aspecto, que da lugar a importantes modificaciones legislativas, suscita el interés de los medios de comunicación, no por un mero afán informativo, sino como instrumento de apelación al sector femenino de la sociedad, en un intento de lograr su adhesión a las directrices que señala el nuevo régimen y que se encuentran, además, refrendadas por la postura de la Iglesia con respecto al papel de la mujer.

El objetivo prioritario que se persigue en este aspecto es la reincorporación de la mujer al hogar y el abandono de los puestos de trabajo que, una vez finalizada la guerra, han de ocupar de nuevo los hombres. El logro de este objetivo, y la formación de la mujer española en general, se encomienda principalmente a la Sección Femenina de Falange que, junto con Auxilio Social, constituye una organización de relevante importancia, tanto durante la guerra como durante la posguerra. La aceptación social de su labor-que no siempre se ve con buenos ojos- es fundamental para la consecución de su programa formativo, y éste es, probablemente, el motivo de que sus actividades ocupen el principal punto de interés en el discurso de la prensa dedicada a la mujer, con prioridad incluso al dedicado al trabajo del hogar.

Atendiendo a las particularidades específicas de los distintos tipos de actividades de la mujer a que se refiere la prensa de la época, hemos

${ }^{3}$ En líneas generales, podemos considerar con Adolfo Perinat y $\mathbf{M}^{\prime}$ Isabel Marrades, que "Revistas femeninas son aquellas que, ya sea por su título o subtítulo, ya sea por declararlo así sus redactores, o ya sea por su temática, tienen como principal destinatario a la mujer". (Mujer, prensa y sociedad en España. 1800-1939, Madrid, Centro de Investigaciones Sociológicas, 1980, pág. 56.)

4 Valgan como ejemplo las siguientes palabras de Pío XII: "Dios ha dado a la mujer la misión sagrada y dolorosa, pero fuente a la vez de purísima alegria, de la maternidad, y a la madre está confiada, antes que a nadie, la primera educación del niño en los primeros meses y años". (Acción Católica Española: Colección de Enctclicas y documentos pontificios, Madrid, Publicaciones de la Junta Técnica Nacional, 1955, 5^ ed., pág. 977.) Y de manera aún más explícita sobre el trabajo de la mujer: "Mirad aquella mujer que, por aumentar el salario del marido, se va también ella a trabajar en la fábrica, dejando durante su ausencia, abandonada la casa; y ésta, tal vez ya de por sí escuálida y angosta, se toma aún más mísera por la falta de cuidado; los miembros de la familia trabajan separadamente por los cuatro ángulos de la ciudad y en horas distintas; casi nunca se encuentran juntos ni siquiera para comer, ni aun para el reposo después de las fatigas de la jornada, mucho menos para la oración en común. ¿Qué queda de la vida de familia? y ¿qué atractivos puede ella ofrecer a sus hijos?". (Ibidem, pág. 1.200). 
establecido una clasificación por áreas que corresponde a los siguientes referentes:

Trabajo del hogar, que engloba las actividades que desarrolla la mujer como esposa y madre y como ama de casa; trabajo social, correspondiente a las ocupaciones a las que se dedica la mujer, y especialmente las afiliadas y colaboradoras de la Sección Femenina y Auxilio Social, como consecuencia de la guerra, y con una finalidad prioritariamente social; trabajo remunerado, en talleres, fábricas, oficinas, etc., con finalidad puramente lucrativa; trabajo artesano, variedad del anterior, puesto que persigue también un beneficio económico, pero orientado hacia actividades tradicionalmente consideradas propias de la mujer, como los trabajos manuales, labores del campo, etc. ${ }^{5}$; trabajo intelectual, de escritoras, investigadoras, profesoras de Universidad, etc.; y trabajo de magisterio.

El primer hecho que destaca al observar el tratamiento que otorgan las revistas femeninas de la posguerra al trabajo de la mujer es la desigualdad cuantitativa que recibe cada una de las áreas en que hemos clasificado el referente, pues, mientras el trabajo social ocupa -con gran diferencia- el centro de interés, seguido por las actividades del hogar y remuneradas, los trabajos artesanos, intelectual y de magisterio sufren una relegación desproporcionada con respecto a las tres primeras áreas mencionadas ${ }^{6}$.

La designación de cada uno de estos tipos de trabajo de la mujer se realiza mediante la utilización de una serie de elementos léxicos que poseen un núcleo sémico común, lo que permite la integración de todos ellos en el paradigma /TRABAJO/ $\Gamma$. Este núcleo, o invariante sémica, está constituido por una serie de rasgos denotativos ${ }^{8}$ que deben

S Ésta es, quizá, el área referencial más heterogénea, pero las actividades comprendidas en ella reciben un tratamiento unitario en la prensa de la época, como demuestran las siguientes palabras: "En todos los tiempos la mujer participo, como el hombre, en el trabajo, sobre todo, en determinados sectores sociales y en cierta clase de trabajos. como el trabajo agricola, hilados, domésticos, etc. De los tiempos modemos son la oficina y la fábrica". (Dr. M. Blanco Otero, "Influencia del trabajo de la mujer", Consigna, $\mathrm{n}^{\circ}$ 50; marzo, 1945.)

6 Especialmente sorprendente resulta la proporcionalmente escasa frecuencia, con respecto a otras áreas de actividad, de las referencias al trabajo de magisterio, teniendo en cuenta que es el objetivo principal de una revista mensual -Consigna-, publicada desde finales de 1940.

7 El grupo de lexemas que se presentan como equivalentes -parcialmente, al menos- en el uso de un tipo de discurso concreto y en una época determinada. constituye un paradigma, concepto éste que diferenciamos del de campo semántico, que englobaría un conjunto de paradigmas y establecería las equivalencias semánticas en la lengua.

* Consideramos el rasgo o sema denotativo como un rasgo conceptual en la lengua: es decir, como un rasgo de contenido estable del lexema frente al rasgo connotativo, que constituye el valor de uso de dicho lexema. 
ser comunes a todos los lexemas integrantes del paradigma; es decir, por aquellos rasgos que indefectiblemente deban encontrarse en el semema de todos y cada uno de los elementos léxicos situados sobre la isotopía vertical de "trabajo", y que, en este caso, serán:

'actividad', 'humana', 'con esfuerzo' y 'para la consecución de un fin'.

Además del núcleo sémico, cada semema puede contener otros rasgos denotativos de acuerdo con su significado en la lengua ${ }^{9}$, que pueden encontrarse alterados o modificados en el discurso en función de la connotación ${ }^{10}$.

Así pues, TRABAJO es el archilexema cuyo archisemema contiene a los sememas expresados por una serie de significantes lexemáticos, sememas integrados por ese significado archilexemático más alguna determinación complementaria.

La distribución de uso de cada uno de los elementos léxicos en la designación de cada área obedece, en general, a su significado denotativo, por lo que encontramos, por ejemplo, la palabra estudio referida únicamente el trabajo intelectual, o empleo y colocación sólo en la designación del remunerado.

Pero el semema del sustantivo posee muchas veces una significación abstracta que se concreta e intensifica en el discurso gracias a los rasgos connotativos que le aportan los sememas de los elementos con los que mantiene relaciones sintagmáticas, de modo que un mismo sustantivo puede tomar en el discurso sentidos no sólo diferentes, sino incluso opuestos, según el significado de los elementos con los que entabla relaciones sintagmáticas, y en función de la actitud del emisor del mensaje ante el referente designado. Así, por ejemplo, podemos encontrar la palabra trabajo positivamente valorada en la designación de las actividades del hogar, y rodeada de connotaciones negativas en la del remunerado:

1.- "Por eso, en estos días penitentes de Cuaresma (...) debe la mujer poner la mano sobre el corazón y examinar, imparcial, severa y profundamente, si a lo largo del año sabe cumplir ese trabajo inexcusable y salvador, que es, en definitiva, el trabajo mejor remunerado a la hora

y La validez del Diccionario como medio de determinar el significado de una palabra en la lengua nos parece discutible. Sin embargo, resulta operativo desde el punto de vista metodológico y es el instrumento más objetivo, aun admitiendo sus limitaciones, para determinar el significado "normal", estable dentro de una comunidad lingüística, de una palabra. Su empleo en este sentido es defendido, entre otros, por Alain Rey: Le lexique: images et modeles. Du dictionnaire à la lexicologie, Paris, Armand Colin, 1977, pág. 48.

10 Consideramos aquí la connotación no como opuesta a la denotación, sino como su complemento, como portadora de valores segundos, pero no secundarios, siguiendo a Catherine Kerbrat-Orecchioni: La connotation, Lyon, Presses Universitaires de Lyon, 1977. 
inapelable del mañana..." (José de Juanes, "Confidencias", Medina, $\mathrm{n}^{\circ}$ 105; 21, marzo, 1943).

2.- "Vosotros sabéis mejor que nadie (...) cómo la felicidad de la mujer en los hogares modestos sucumbe rápidamente bajo el peso de las necesidades y la prosa de ese trabajo abrumador que prematuramente las envejece". ("Discurso del Caudillo en la II Concentración Nacional de la S.F.", Consigna, n 43, 1944).

En efecto, tanto la denotación como la connotación aportan información sobre el sentido que toma la palabra inserta en un enunciado, puesto que al significado "normal" y considerado como estable dentro de la comunidad lingüística, se le añaden las significaciones segundas que proceden del valor que adquiere esa palabra en función del contexto.

Entre los sustantivos que se emplean en la Prensa Femenina de la posguerra española para designar el trabajo de la mujer, destaca, por lo significativo, el uso de misión.

Misión ocupa el tercer puesto en frecuencia de empleo general, después de trabajo y labor ${ }^{11}$. En el caso de trabajo y labor, la falta de intensidad de sus significados denotativos favorece el dirigismo semántico, que se logra por medio de las connotaciones que añaden un sentido segundo al semema mediante la asociación sintagmática del lexema con determinados modificadores en el discurso. Sin embargo, el uso de misión, que posee un significado mucho más intenso, es, probablemente, el más llamativo de los que encontramos entre los lexemas integrantes del paradigma /TRABAJO//.

El DRAE, en las ediciones $15^{\mathrm{a}}(1925), 16^{\mathrm{a}}(1939), 17^{\mathrm{a}}(1947)$ y $18^{\mathrm{a}}$ (1956), define misión como "Acción de enviar", "Poder, facultad que se da a una persona de ir a desempeñar algún cometido", "Salida, jornada o peregrinación que hacen las religiosas y varones apostólicos de pueblo en pueblo, o de provincia en provincia, predicando el Evangelio" (...), "Comisión temporal dada por un gobierno a un diplomático o agente especial para determinado fin".

Prácticamente iguales a ésta son las definiciones del Diccionario General Ilustrado de la Lengua Española, de 1945,y del Diccionario Ideólogico de la Lengua Española de Casares. Sin embargo, la 19a edición del $D R A E$, de 1970, incorpora, como tercera acepción, la de "Cometido", que se mantiene en la $20^{2}$ edición, de 1984.

11 Estos datos corresponden a un trabajo más amplio titulado El vocabulario del trabajo de la mujer en el lenguaje de la Prensa Femenina española (1939-1945), en vías de publicación. 
En su Díccionario de Sinónimos de la Lengua Española, Gili Gaya no registra el artículo misión, pero en cometido remite a "Comisión, encargo, obligación, misión", y añade: "Cometido y misión son vocables escogidos, de uso culto".

La posibilidad de considerar el lexema misión como integrante del paradigma /TRABAJO//, que avala la equiparación semántica con cometido, se ratifica en la definición del Diccionario de Uso del Español, de María Moliner, que, sub voce misión, dice: "Obra o función trascendental que una persona o una colectividad se siente obligada a realizar en bien de alguien, o que le está asignada por la Providencia", "Trabajo de evangelización llevado a cabo, particularmente, en países lejanos o atrasados", "Cualquier otro trabajo benéfico que una persona o comisión va a realizar a un país lejano o atrasado".

Según las definiciones que hemos visto, la palabra misión tiene un significado denotativo cosntituido por el núcleo sémico común al paradigma /TRABAJO//, con precisión del rasgo que indica finalidad como 'para la consecución de un fin social o espiritual', más los rasgos específicos 'moralmente obligatorio' y 'con sentido religioso'. Aunque no todas las acepciones señalan explícitamente este 'sentido religioso', parece muy probable la contaminación sémica de este rasgo a todo el uso de misión, como se deduce de las palabras de Rafael $\mathrm{M}^{2}$ Baralt que, en su Diccionario de Galicismos, de 1874, comenta: "Ahora que no hay frailes todo el mundo tiene mision; y así tropezamos a cada instante con la misión del poeta, la misión del filósofo, la misión de la prostituta, la misión de cuanto Dios críb, bueno o malo. No parece sino que todo bicho viviente se ha metido a diablo predicador"12.

Este sentido religioso de misión se mantiene en la época que nos ocupa, como se puede comprobar en las citas que reproducimos a continuación:

3.-“(...) Para ayudar en esta mision (la palabra no es casual, ya que misionera, difusora del ideal, ha de ser la voz de Magisterio) y con este sentido orientador nunca doctrinal, se inicia esta colaboración." (Miguel Moreno Borondo, "Temas laborales-Antecedentes", Consigna, $\mathbf{n}^{\circ}$ 1; diciembre, 1940).

4.- "Todos estamos dispuestos a llegar hasta el supremo sacrificio por cumplir nuestra misión. Misión en el neto sentido de la palabra, en sentido religioso". ("Jose Antonio dijo", Editorial, Medina, n' 161; 16, abril, 1944).

12 Rafael M' Baralt: Diccionario de Galicismos, Caracas, 1874, pág. 361. Apud M* Paz Battaner Arias: Vocabulario polltico-social en Esparia (1868-1873), Madrid, Anejo XXXVII del Boletin de la Real Academia Española, 1977, pág. 502. 
5.-"Continuando nuestra misión -misionero hay que sentirse en estos tiempos de materialismo, cuando se intentan empresas espirituales- de propagar la costumbre de hacer sentir y vivir el hogar propio con dulce y pacífica intimidad (...)" (Rafael Benedito, "La música en el hogar", Consigna, $\mathrm{n}^{\circ} 51$; abril, 1945).

A pesar de la relación de cuasi-sinonimia que establecen las definiciones de los diccionarios consultados entre misión y cometido, la Prensa Femenina de la posguerra española demuestra una clara preferencia de uso por la primera, mientras que el empleo de cometido es prácticamente inexistente.

Por lo que respecta a la frecuencia de uso, misión es la palabra más utilizada en la designación de los trabajos del hogar y de magisterio; ocupa el tercer lugar, tras labor y tarea, en la del trabajo social; es poco frecuente en la designación del trabajo artesano y no la hemos encontrado en ningún caso para designar el trabajo intelectual.

Mención especial merece la presencia de misión en el área del trabajo remunerado de la mujer, en la que, con dos únicas ocurrencias, se niega explícitamente la posibilidad de denominar misión a este tipo de actividad:

6. - No; ninguna mujer realmente sensible va por gusto a la oficina o al taller. Cumple su misión humana y realiza la que la vida o el Estado le encomiendan, pero siempre en ansia de hogar". (Esperanza Ruiz-Crespo, "No sólo de taquimeca puede vivir la mujer", $Y, n^{\circ} 34$; noviembre, 1940).

7.-"Por eso ella no debe luchar nunca por la existencia, porque no es su misión, ni biológicamente está preparada para ello". (Dr. José Botella Llusiá, "Peligros de la civilización moderna para la biología de la mujer", Consigna, n² 27; abril, 1943).

La ausencia de uso de misión en la designación del trabajo remunerado demuestra la fuerza de su significado denotativo, que no sufre prácticamente ninguna alteración sémica en el discurso, al contrario de lo que ocurre con palabras de significado extenso como labor, trabajo, e incluso tarea, que, como hemos visto antes, pueden tomar sentidos totalmente distintos en función de las connotaciones de que se las rodee en el discurso.

En efecto, con frecuencia, el significado denotativo de la palabra se ve alterado en el contexto de acuerdo con el referente designado, 
de modo que se establece una relación de equivalencia en el discurso entre palabras que no pueden ser consideradas como sinónimos en la lengua.

Así ocurre que encontramos en el discurso de la Prensa Femenina un uso de misión que, en la designación del trabajo social de la mujer, resulta perfectamente intercambiable en el contexto con otros lexemas pertenecientes al paradigma /TRABAJO//, como deber, obra, labor, oficio, tarea, etc.

Por ejemplo, es frecuente la alusión a la misión militar de la mujer:

8.-"Finalmente, después de compartir todos los trabajos con el hombre en la vida civil, la mujer moderna se ha incorporado en esta guerra a las misiones militares. Todavia no empuña el fusil ni dispara el cañón". (Fernando Roa, "Las chicas de los reflectores", Fotos, n 386; 22, julio, 1944).

Pero de la misma manera, encontramos una empresa militar, una función de guerrera y, de nuevo, un servicio militar:

9." Ahora oímos todos los días: "El Ejército", "antimarxismo", "Estado totalitario", "me declaro fascista"... y centenares de cosas más. Pero todo como un torbellino, como una algarabía (...) Más parece eso la invitación a un baile de disfraces que la invitación para embarcarse en una empresa religiosa y militar de hacer historia". (Discurso de Pilar Primo de Rivera en el VI Consejo Nacional de la S.F., Consigna, $n^{\circ}$ 12; enero, 1942).

10.-"La mujer falangista dio ejemplo de entereza, de conciencia del deber, de sentido preciso en cuanto a su función de guerrera". ("Consigna", Medina, no 16; 3, julio, 1941).

11.-“El servicio de la mujer es heroico, militar, pero femenino. (...) es ilimitado el campo de estas actividades puramente femeninas. La religión, la beneficencia, los hospitales, la puericultura, los oficios, la música, el arte, la oficina. En todo lugar es útil y necesaria una mujer". ("Destino de la mujer falangista", Medina, n 20; marzo, 1941).

Sin embargo, esta misión militar que la mujer ha debido desempenar durante la guerra civil y tiene que seguir realizando en los países beligerantes que participan en la segunda guerra mundial, se convierte en pacificadora, capaz de lograr la unidad entre los hombres, durante la posguerra: 
12.-"Han de lograr - jmirad qué alta mision!- la unidad entre los hombres (...) Buen aprendizaje para su misión difícil y apasionante". ("Instructoras", Medina, no $121 ; 11$, julio, 1943).

Y en el mismo sentido encontramos el uso de función:

13.-"Certeramente asignaba a las mujeres el General Muñoz Grande, en su magnífico discurso de apertura, la función excelsa de pacificadora". (Ángel B. Sanz, "Escuelas del hogar”, Y, n 25; febrero, 1949).

La obligación moral que, como hemos visto, constituye un rasgo característico del significado de misión, y que se manifiesta en la perífrasis de obligación "han de lograr" del texto 12, se explicita también contextualmente en el uso de deberes, modificado por la proposición adjetiva "que la Patria reclama":

14.-"Las mujeres, que en la guerra hallaron puestos en los que prestar servicios abnegados, en la hora de la paz se disponen a cumplir con los nuevos y sacrosantos deberes que la Patria reclama". (Alfredo R. Antigüedad, "Franco condecora a nuestras camaradas", Fotos, $\mathbf{n}^{\circ} 119 ; 10$, junio, 1939).

Y del mismo modo, en el uso de obra y empresa, que se presentan en el contexto con connotaciones de obligatoriedad moral que dimanan del recurso a criterios de autoridad representados por Jesucristo, la Iglesia y el Caudillo:

15.-"Jesucristo espera de vosotras esa obra [el apostolado]. La Iglesia os la confía. El Caudillo de España os la recomienda, como una necesidad de la Patria. Y vosotras respondéis bien a tan altas invitaciones y os esforzáis en realizar tal empresa a costa de los trabajos y sacrificios que fueren precisos". (Editorial, La Mujer de Acción Católica, $\mathbf{n}^{\circ} 41$; abril, 1941).

Igualmente, la Iglesia representa el criterio de autoridad que permite la connotación de oficio en este sentido de obligación moral: 
16.-“(...) pensando en la responsabilidad contraída por la Rama de las Mujeres de Acción Católica, al aceptar tan honroso oficio como les propone la Iglesia, de ir moldeando las almas de los niños para el apostolado, conviene que veamos en cada Diócesis y en cada Parroquia cómo se van cumpliendo todas las normas dadas para este apostolado, tan hermoso, tan sencillo y de tanta gloria de Dios y de las almas". ("Niños", Senda, n 25; junio, 1943).

Por otro lado, la misión de la mujer consiste, esencialmente, en una actividad de formación:

17.- "Esta es la importante mision de la Sección Femenina: formar mujeres en el amor de Dios, haciéndoles ver cada vez más bello el dulce rincón del hogar, sitio donde han de rendir sus más altos valores espirituales". ("Estampas de un albergue de Juventudes Femeninas", Medi$n a, \mathrm{n}^{\circ} 238 ; 7$, octubre, 1945).

Pero también su oficio es "ir moldeando las almas de los niños para el apostolado", como hemos visto en el texto 16, y su labor es de "preparación de la mujer":

18. “Completan, naturalmente, y coronan esta formación femenina las clases de Religión, Moral, Pedagogía infantil, etc., etc..., que dan el valor intelectual y religioso adecuado a esta labor trascendental de preparación de la mujer a su tarea fundamental de madre de familia de tan profunda influencia en el mundo". (Carmen Pardo, "La especialización de la mujer para el hogar", Senda, $n^{\circ} 26$; julio-agosto, 1941).

Y de formación son tanto la obra como la tarea de la mujer, identificadas sinonímicamente en el contexto:

19.-"Claro que en esta obra de formación no vamos solas, porque diariamente invocamos al Espíritu Santo (...) Toda esta tarea es difícil y nos rodearán enemigos a la izquierda y a la derecha. Pero iqué puede importarnos la dificultad inmediata, si al cabo del tiempo no habrá de ella ni memoria y, en cambio, quedará hecha nuestra obra? ("Del discurso inaugural del IV Consejo Nacional de la S.F., pronunciado por P.P. de Rivera", $Y, \mathbf{n}^{\circ} 24$; enero, 1940). 
La misión social de la mujer se presenta, además, en el contexto como de importancia, como se infiere de los textos 12 ("alta") y 17 ("importante"), pero este rasgo se actualiza contextualmente también en el uso de función, calificada de "excelsa" en el texto 13, en el de labor, que se califica de "trascendental" en el 18; así como en el de obra y papel:

20.-“(...) y en torno a la tarea del Consejo resplandece una aureola de paz moral, una fe sincera y una confianza en la protección del cielo para la obra falangista, tan fundamentalmente cristiana en su intento de superación moral, de justicia y hermandad". (C. W., "Impresión y reflejo lejano del VII Consejo Nacional", Medina, $\mathrm{n}^{\circ}$ 98; 31 , enero, 1943).

21.-"(...) y en esta misión de afianzar cada vez más la fe en España es la mujer la que ha de desempeñar el papel más importante". (La Presidenta Nacional, "Amor a la Jerarquía", La Mujer de Acción Católica, $n^{\circ} 37$; agosto, septiembre, octubre, 1940).

La finalidad social y política de misión se explicita en el contexto:

22.-"En la mujer española la entrega a esta tarea de orden intelectual (incluimos en ésta la preocupación activa en una misión de tipo político o social) no ha supuesto, ni supone nunca una desvalorizacion de sus esencias femeninas, un relegar a segundo término sus virtudes específicas, o un perder su fisonomía peculiar". (José María del Moral, "Las mujeres universitarias y la minoría rectora", Medina, $\mathrm{n}^{\circ} 212 ; 8$, abril, 1945).

Esa misma finalidad caracteriza a deberes ("que la Patria reclama"), en el texto 14; a obra ("necesidad de la Patria"), en el 15; a empresa ("de hacer historia"), en los textos 9 y 15 ; o a destino, que incluso se utiliza como equivalente semántico de misión en el siguiente:

23.-"Puede también una mujer cumplir destino político propiamente (...) Que una alta misión política puede cumplirla la mujer sin abandonar su destino propio [el hogar] (...) podemos decir -aun pensando (...) en la posibilidad de un destino directamente político- que la consigna 
suprema para las mujeres sería (...) HAY QUE SER MADRES". (Carlos Alonso del Real, "La Mujer en el destino del pueblo", Consigna, $\mathrm{n}^{\circ} 33$; octubre, 1943).

El sentido religioso, que constituye un rasgo del significado de misión y que se explicita en el texto 17 ("formar mujeres en el amor de Dios"), se hace extensivo al sentido que toman en el discurso los demás miembros del paradigma. Así, deberes se califica de "sacrosantos" (texto 14), empresa de "religiosa" (texto 9), obra de "tan fundamentalmente cristiana" (20), papel se equipara a la "misión de afianzar cada vez más la fe en España" (21), la tarea y la obra de la mujer son apoyadas y compartidas por el Espíritu Santo (19), y tarea se califica además de "misional" y "tan cristiana", como veremos a continuación:

24.-"En el recuerdo de un Santander en brasas. Tarea misional de una S.F. ejemplar". ( $Y, \mathrm{n}^{\circ} 39$; abril, 1941).

25.-"Y es tanto el interés y abnegación que estas camaradas han puesto en tan cristiana tarea, que en poco tiempo es muy alentador el balance de las obras allí realizadas". ("La Sección Femenina de Santander realiza una importante labor en el Albergue de Mendigos instalado en la capital", Medina, $n^{\circ} 155 ; 5$, marzo, 1944).

En cuanto al rasgo que hemos señalado como 'con esfuerzo', se puede observar tanto en el uso de misión como en el de tarea, calificadas ambas de "difícil" en los textos 12 y 19, respectivamente.

La equivalencia semántica que se establece en el discurso entre todos los elementos léxicos que constituyen el paradigma /TRABAJO SOCIAL DE LA MUJER// es especialmente significativa en el caso de misión y tarea, palabra esta última que modifica notable y constantemente su significado denotativo. Pues si tarea tiene el significado de actividad obligatoria (no en el sentido moral, sino en el material) y delimitada tanto cuantitativa como temporalmente, la equivalencia sémica con misión que adquiere en el uso contextual la convierte en una tarea en el más estricto sentido orteguiano, en el sentido de "programa de vida"13, que es el que adopta la Falange, y más concretamente José Antonio Primo de Rivera, quien al hablar de "lo nacional", realiza un

13 A la tarea como "programa de vida" se refiere José Ortega y Gasset en La rebelión de las masas. Obras completas. Tomo IV, Madrid, Revista de Occidente, 1947, págs. 11285, cit. en pág. 238. 
paralelismo entre misión y tarea que se confirma plenamente en el uso que de ambas palabras hemos visto: "Lo nacional, dicho como propaganda de una misión, de una tarea, no como vago presupuesto de las tareas de todos los partidos"14.

Por lo que respecta a la designación del trabajo del hogar, misión es, como hemos dicho, el elemento del paradigma /TRABAJO// que presenta mayor número de ocurrencias, seguido por tarea y labor, muy igualadas en frecuencia de uso.

El significado denotativo de misión se mantiene en el discurso sin modificaciones sustanciales, como confirma el hecho de que designe el trabajo de la mujer como esposa y madre, pero nunca su más prosaica actividad de ama de casa. Sin embargo, la encontramos en el discurso como equivalente semántico de palabras de significado tan diferente como cargo, carrera, destino u oficio, entre otras.

La obligatoriedad moral que supone el significado de misión se hace extensiva al sentido que toman en el discurso los demás elementos del paradigma y, como en la designación del trabajo social, en la mayoria de los casos esta obligación va estrechamente ligada a designios divinos:

26.-"De parte de las madres, el fin es: formarse más y más para el ejercicio del cargo sublime que el Señor les ha confiado. ¿Es tanta la grandeza de la maternidad y son tantos los deberes de la madre! ("Semana de la Madre", La Mujer de Acción Católica, n 42; mayo, 1941).

27.-"[La Semana de la Madre] Tiene como fin exaltar la figura de la Madre, hacer que sienta su grandeza, la inmensa labor que el Señor le ha confiado, y que, sintiéndola, viva sobrenaturalmente su vida verdaderamente cristiana, siendo así modelo de esposa y de madre". ("Semana de la Madre", La Mujer de Acción Católica, nº 23; mayo, 1939).

28.-"Y, al crearla, Dios le asigna [a la mujer] un papel ilimitado de ayuda para el hombre”. (M.L. Fuertes, “Mujer y Universidad”, Senda, n' 32; marzo, 1944).

A la máxima responsabilidad de la mujer como esposa y madre se hace referencia con un uso de empresa como equivalente total de misión:

14 José Antonio Primo de Rivera: "Circular a todas las Jefaturas territoriales provinciales y de las J.O.N.S.", en Obras de José Antonio Primo de Rivera. Edición cronológica, recopilación de Agustín del Río Cisneros, Madrid. Delegación de la Sección Femenina de F.E.T. y de las J.O.N.S., 1964, págs. 934 y 935. 
29.-“(...) parte esencial e importantísima de esta actuación os corresponde a vosotras, mujeres españolas, que, cumpliendo elevada misión de esposas y madres en el hogar familiar realizáis una empresa de má. ximo honor y de máxima responsabilidad". (Dr. Navas Migueloa, "Niños. La mujer y la Puericultura”, Medina, no 18; 17, julio, 1941).

También destino se califica de "propio" en el texto 23. Y para designar la actividad de la mujer madre como algo intrínseco a su naturaleza, se emplean obligación, obra y puesto:

30.-“(...) saber ser madre es, ante todo y sobre todo, obligación que la mujer lleva aparejada a su ser desde que nace". (José Juanes, "Dolor y gozo de la maternidad", Medina, n 90; 6, diciembre, 1942).

31.-"Y tiene [la mujer] su "emulación" principal en la forja de hombres, que a su cuidado y solicitud están encomendados. Esta obra es superior a la construcción de catedrales y castillos". (A García Figar, “¿Decía usted?”, Medina, n 232; 26, agosto, 1945).

32.-"Pero sobre todo tenéis que encauzar la voluntad de las afiliadas hacia la casa, hacia la familia, que es el único puesto que las mujeres tienen asignado en las tareas de la Patria". ("Pilar Primo de Rivera dijo a los primeros Consejos Provinciales de la Sección Femenina en toda España", Medina, no 178; 13, agosto, 1944).

La finalidad social y política que encierra la misión de la mujer en el hogar se hace explícita especialmente en el ejemplo siguiente:

33.-"La familia es la célula preciosa de la sociedad. En ella, en el hogar, tiene la madre una misión importantísima: es la guardiana, la defensora de la familia, institución preciosísima, la primera de todas". (Don Baldomero Jiménez, "La madre en el hogar", Senda, no 5; mayojunio, 1941).

Pero también se deduce del uso de tarea en el texto 18 ("de tan profunda influencia en el mundo"), de obra en el texto 31 ("superior a la construcción de catedrales y castillos"), de puesto en el 32 ("único que las mujeres tienen asignado en las tareas de la Patria"), de deber y servicio: 
34. "El verdadero deber de las mujeres, para con la Patria, es formar familias con una base exacta de austeridad y de alegría en donde se fomente todo lo tradicional, en donde se canten villancicos el día de Navidad alrededor de un Nacimiento". (Pilar Primo de Rivera, "Consigna", Consigna, $\mathrm{n}^{\circ} 11$; diciembre, 1941).

35.-“Al levantar el nivel social y sublimar los ideales del hogar, presta [la mujer] a la sociedad un servicio tan fundamental y tan trascendental, que supera a las maravillas de la ciencia, a los portentos de la industria y a las bellezas del arte". (Carmen Boj, "La mujer y la sociedad", Medina, no 142; 5, diciembre, 1943).

El sentido religioso resulta implícito en el uso de misión, aunque a menudo, se manifiesta también explícitamente en el discurso:

36.-"Y así, la mujer, en el recuerdo del humano dolor de la Virgen Maria, sabe también su misión abnegada, sencilla, heroica". (Editorial, Medina, $n^{\circ} 4 ; 10$, abril, 1941).

El mismo sentido religioso de misión se desprende del uso contextual de empresas ("espirituales"), en el texto 5; de cargo, en el texto 26 ("sublime que el Señor les ha confiado"), labor, en el 27 ("inmensa que el Señor le ha confiado"), papel, en el 28 (que "Dios le asigna"), función ("sagrada"), oficio (que "exige tanta abnegación"), o tarea ("que da gloria después..."):

37.- “Los sillines duros, estrechos y alargados, podrían dar lugar, y han dado en algunas ocasiones, al endurecimiento excesivo de los músculos del periné, que después habrían de dificultar considerablemente la fisiológica normalidad de la más elevada y sagrada función de la mujer: la maternidad". (Fernán Pérez, "Señorita, monte usted en bicicleta", iHola!, $n^{\circ} 68 ; 15$, diciembre, 1945).

38.-"El oficio de madre es lo suficientemente amplio y hermoso, exige tanta abnegación y vigilancia como para no abarcar también el de profesor". (Tania, "No hagáis vosotras mismas...", Misión, $n^{\circ} 232 ; 25$, marzo, 1944).

39.-“El gozo de ser madre por el dolor y el sacrificio es tarea inexcusable femenina que da gloria después, cuando en el más allá se sopesen martirios y merecimientos". (José Juanes, "Dolor y gozo de la maternidad", Medina, n" 90; 6, diciembre, 1942). 
Como actividad de gran importancia, se usa misión calificada de "verdadera", igual que deber en el texto 34 , y carrera:

40.- "La verdadera mision de la mujer es crear hombres valerosos. Saber infundir en los hombres este valor que ellas ni poseen ni deben poseer, y mantener en ellos en todo momento este valor moral de la violencia física, al que ellas, nunca o casi nunca, deben llegar". ("El valor femenino", Medina, $\mathrm{n}^{\circ}$ 7; 1, mayor, 1941).

41. "La verdadera carrera de la mujer es la de madre de familia. Estamos de acuerdo que es a la que deben todas aspirar, exceptuando un escaso número que otras vocaciones más sublimes puedan acaparar". (“Carreras para la mujer”, $Y, n^{\circ} 44$; septiembre, 1941).

En el texto 33, mision se califica de "importantísima", como en el 29, en el que también empresa se califica como "de máximo honor y de máxima responsabilidad". La misión de la esposa y madre se considera "esencial" en el texto que presentamos a continuación:

42.-"Desde luego, la misión esencial de la mujer es la de ser esposa y madre, y a cualquier clase social que perternezca, debe concentrar sus energías en el hogar". (Carmen Buj, "La mujer y la sociedad", Medina, $\mathrm{n}^{\circ} 85 ; 1$, noviembre, 1942).

Pero también es "elevada" su función (texto 37), "inmensa" su labor (texto 27), "ilimitado" su papel (texto 28), "único" su puesto (texto 32), "fundamental" su tarea (texto 18), "fundamental y trascendental" su servicio (texto 35 ), el "más alto" su cometido, "grande" su creación o "suprema" su ocupación, como veremos en los textos siguientes:

43. -"(..) hay cuidados y profesiones que dan a la mujer "un papel" y que pueden contribuir a la sana formación de su espíritu, en el cumplimiento de su más alto cometido, sobre todo hasta que suena, para ella, esa otra hora de carácter más trascendente y definitivo". (Elsa Kiepura, "Los "papeles" de la mujer", Mujer, n 28; octubre, 1939).

44. -"La gran obra del hombre es la ciencia, el arte, la técnica, el Estado: en una palabra, la cultura objetiva; la gran creacion de la mujer es el hogar (...) Pero el hogar, última consecuencia de la maternidad, es la gran creación de la mujer, que en ella alcanza plenitud vital". ("Mision de la mujer", Destino, $n^{\circ} 131 ; 20$, enero, 1940). 
45.-"El hogar es la suprema ocupación de la mujer. Pero de ningún modo debe considerarse fracasada una mujer que no se casa". ("El ocio es el peor enemigo de la mujer", Mujer, $\mathrm{n}^{\circ} 72$; junio, 1943).

La dificultad, como expresión del rasgo denotativo 'con esfuerzo', que observábamos en el área del trabajo social de la mujer, toma en el del hogar un sentido más espiritual con la alusión a la abnegación (textos 36 y 38), a los martirios (texto 39) y al valor moral (texto 40).

Los ejemplos del uso contextual de los distintos elementos léxicos que integran el paradigma /TRABAJO DE LA MUJER EN EL HOGAR// demuestran el mantenimiento en el discurso del significado denotativo de misión, aunque, como ocurría en el área del trabajo social, se agrega un rasgo, 'de importancia', que no podía deducirse de las definiciones de los diccionarios consultados. Este significado de misión contamina el sentido que toman los demás elementos léxicos que conforman el paradigma, de manera que llega a producirse una equivalencia sémica entre ellos en el discurso.

No vamos a detenernos en el empleo de misión para designar los trabajos artesano y de magisterio, que resultan poco interesantes por el mínimo tratamiento que reciben en la prensa, pero ofrecemos a continuación dos ejemplos característicos:

46. “Esta misión [el renacimiento de la artesanía] jay! a nadie incumbe como a la mujer española de nuestros días. (...) [Los hogares españoles] pueden ser hoy también los que nos señalen la obra nueva artesana. En descubrirlos, respetarlos e incorporarlos otra vez a la vida, consiste una de las misiones más elevadas que puede tener actualmente la mujer". (Cecilio Barberán, "Las mujeres ante el renacimiento de nuestra artesania", Medina, n' $154 ; 27$, febrero, 1944).

47.-“La Maestra Rural, tiene como todas las demás, la misión augusta de formar las almitas blandas como la cera de los niños a ella encomendados y hacer de ellos cristianos que sean honra de nuestra Patria".

("Enseñanza. La maestra rural", Senda, n 4; abril, 1941).

Como hemos podido comprobar, el significado que de misión ofrecen las definiciones de los diccionarios queda plenamente confirmado por el uso en el discurso, con lo que el semema "misión" resulta conformado por los semas 'actividad', 'humana', 'con esfuerzo', 'para la 
consecución de un fin social y espiritual', 'moralmente obligatorio', 'con sentido religioso', y, además, por el rasgo connotativo 'de importancia'.

Tan significativo como el mantenimiento contextual del significado denotativo resulta el rechazo a emplear la palabra para designar los trabajos remunerado e intelectual de la mujer. Sin embargo, este respeto por el significado de misión no se hace extensivo al de otras palabras, como oficio y puesto, por ejemplo (V. textos 16 y 32), lo que demuestra que la elección de una u otra palabra para la designación de un mismo referente no está motivada únicamente por el significado denotativo, ya que éste puede resultar notablemente alterado por influencia del contexto.

Así, hemos visto que en la designación del trabajo social de la mujer, se encuentran en relación paradigmática, además de misión, los siguientes lexemas: actividad, deber, destino, empresa, función, labor, obra, oficio, papel, servicio y tarea.

Por lo que respecta al eje de articulación del trabajo de hogar, hemos comprobado la presencia en el mismo, junto con mision, de: cargo, carrera, cometido, creación, deber, destino, empresa, función, labor, obligación, obra, ocupación, oficio, papel, puesto, servicio, tarea y trabajo ${ }^{15}$.

El discurso referido a los trabajos social y del hogar presenta, pues, una fuerte redundancia y se convierte en hiperisotópico. La iteración sémica que se produce en el plano sintagmático por medio de la connotación origina una equivalencia semántica en el discurso entre los diversos integrantes del paradigma /TRABAJO// que, si bien poseen forzosamente un núcleo sémico común, no pueden ser considerados sinónimos en la lengua.

Sin embargo, el mecanismo discursivo que se sigue en la designación de ambos referentes es totalmente distinto:

El trabajo del hogar es una actividad tradicionalmente considerada como femenina, y se elige para designarlo con preferencia una palabra -misión-de significado intenso, que deja pocas puertas abiertas a valoraciones parasitarias procedentes del contexto. Una vez identificado el significado de misión con la actividad de esposa y madre, ya sólo se trata de transferirlo, mediante valoraciones connotativas, al resto de los lexemas que, con mayor o menor propiedad, puedan designar el mismo referente.

El trabajo social de la mujer representa, en cambio, una realidad nueva que se trata de consolidar y, por esta razón, es el referente

is Hay que tener en cuenta que estas listas de lexemas en relación paradigmática responden únicamente a un muestreo sobre el uso de misión, y que no pueden considerarse como inventarios cerrados. 
privilegiado, entre todas las actividades de la mujer, en el discurso de la Prensa Femenina de la época. Para designarlo, se eligen dos palabras -labor y tarea-con significados lo suficientemente extensos y "asépticos" como para admitir cualquier tipo de valoración y, así, el sentido que se afianza a base primordialmente de adjetivaciones repetitivas en el discurso es el que va a contaminar también, con pocas excepciones, a los demás lexemas del paradigma. $Y$ este sentido, muy próximo al significado de misión y al de cruzada, llega a consolidarse de tal manera que da origen a una nueva acepción en la definición de destino que, únicamente en la $19^{\text {a }}$ edición del $D R A E$, de 1970, aparece como "Misión histórica de una colectividad".

En definitiva, misión constituye el eje en torno al cual se articulan los paradigmas que designan a los trabajos del hogar y social de la mujer en el discurso de la Prensa Femenina de la posguerra española, pero mientras que en el primer caso es el signo completo el que sirve de soporte de los demás elementos del paradigma, en el segundo, es su significado, transferido a labor y tarea por medio de la connotación, y al resto de los lexemas conmutables con éstos, el que actúa como eje de dicho paradigma.

Glosario De Referencias En Los Textos Aducidos

actividades: 11

cargo: 26

carrera: 41

cometido: 43

creación: 44

deber: 34

deberes: 14,26

destino: 11,23

empresa: $9,15,29$

empresas: 5

función: $10,13,37$

labor: $18,25,27$

misión: $3,4,5,6,7,12,17$

$$
21,22,23,29,33,36 \text {, }
$$$$
40,42,46,47
$$

misiones: 8,46 obligación: 30

obra: $15,19,20,31,46$

obras: 25

ocupación: 45

oficio: 16,38

papel: $21,28,43$

puesto: 32

servicio: 11,35

servicios: 14

tarea: $18,19,20,22,24,25,39$

tareas: 32

trabajo: 1,2

trabajos: 8,15 


\section{Revistas Consultadas}

almanaque De La Madre De Familia. Suplemento anual de El Hogar y la Moda, Batcelona, 1942.

ARTE Y Hogar. Publicación mensual, Madrid, 1943.

Consıgna. Publicación mensual de la Sección Femenina de Falange, Madrid, $n^{\circ} 1$, año I, Diciembre, 1940.

Destino. Politica de unidad. Publicación semanal, Director: Ignacio Agustín, Barcelona, $\mathrm{n}^{\circ}$ 107, (segunda época), 5, Agosto, 1939.

Fotos. Semanario gráfico nacionalsindicalista. Publicación semanal, Fundador y Director: Manuel Fernández Cuesta, San Sebastián, n 97, Año II, 7, Enero, 1939; Editado en Madrid a partir del $n^{\circ} 159$, Marzo, 1940.

El hogar Español. Semanario de amenidades. París, nº 1, Año I, 8, Febrero, 1941.

EL HOGAR Y LA MODA. Publicación mensual, Barcelona, $\mathrm{n}^{\circ} 1.150$ (segunda época), año XXXIII, Marzo, 1941.

¡Hola! Semanario de amenidades, Barcelona, no 1, Año I, Septiembre, 1944.

LECTURAS. Revista de Arte y Literatura. Suplemento mensual de El Hogar y la Moda, Barcelona, n 199, Año XXII, Abril, 1941.

LICEO. Revista del gran mundo. Publicación mensual, Director: Antonio del Cerro, Barcelona, $\mathbf{n}^{\circ} 1$, Año I, Diciembre, 1944.

LUNA Y Sol. Panorama de los hechos y los días. Publicación mensual, Madrid, n 1 , Año I, 15, Mayo, 1944.

MEdina. Semanario de la Sección Femenina de Falange, Director: Carlos J. Ruiz, $\mathbf{n}^{\circ} 1$, Año I, 20, Marzo, 1941.

MIsıÓN. Revista quincenal del Hogar, la parroquia y la escuela. Editada por Acción Católica, Pamplona, $n^{\circ}$ 55, Año III, Septiembre, 1939. A partir del no 106, Año V, 25, Octubre, 1941, publicación semanal.

MUJER. Revista mensual de la moda y del hogar. Director: Baldrich, San Sebastián, $\mathrm{n}^{\circ} 20$, Año II, Enero, 1939.

MUJer DE ACCION CATOLICA. Revista mensual de la Unión Diocesana de Mujeres Católicas de Mallorca, Palma de Mallorca, ${ }^{\circ} 19$, Año III, Enero, 1939.

PARA Nosotras. Publicación de diez números anuales, destinada a la mujer obrera, editada por Acción Catolica, Madrid, n 1, Año I, Marzo, 1944.

SEnDA. Revista mensual del Consejo Superior de Mujcr de Acción Católica de España, Madrid, $n^{\circ} 1$, Año I, Enero, 1941.

$Y$. Revista de las mujeres nacionales sindicalistas. Publicación mensual, San Sebastián, $\mathrm{n}^{\circ}$ 12, Año I, Enero, 1939.

\section{DicCIONARIOS}

Casares, Julio

Diccionario Ideologico de la Lengua Española, Barcelona, Ed. Gustavo Gili, 1959.

Diccionario Ideológico de la Lengua Española, Barcelona, Ed. Gustavo Gili, $2^{4}$ ed., 1977.

Gili Gaya, SaMuel

Diccionario de Sinónimos, Barcelona, Bibliograf, 1958.

Diccionario de Sinónimos, Barcelona, Bibliograf, $7^{4}$ ed. corregida y aumentada, 1980. 
Diccionario General Ilustrado de la Lengua Española, Barcelona, Biblograf, VOX, 1945.

Diccionario General llustrado de la Lengua Española, Barcelona, Biblograf, VOX, $2^{\sharp}$ ed., 1953.

Diccionario General Ilustrado de la Lengua Española, Barcelona, Biblograf, VOX, 3" ed., corregida y ampliada, 1973.

Diccionario General Ilustrado de la Lengua Española, Barcelona, Biblograf, VOX, 1 reimpresión corregida, 1976.

Moliner, Maria

Diccionario de Uso del Español, volumen I (A-G), Madrid, Gredos, 1966.

Diccionario de Uso del Español, volumen II (H-Z), Madrid, Gredos, 1967.

REAL ACADEMIa EsPañola

Diccionario de la Lengua Española, Madrid, 1925, 15ª ed.

Diccionario de la Lengua Española, Madrid, 1939, 16² ed.

Diccionario de la Lengua Española, Madrid, 1947, 17 ed.

Diccionario de la Lengua Española, Madrid, 1956, $18^{a}$ ed.

Diccionario de la Lengua Española, Madrid, 1970, 19 ed.

Diccionario de la Lengua Española, 2 volúmenes, Madrid, 1984, $20^{\circ}$ ed.

Diccionario Histórico de la Lengua Española, tomo I (a-alá), Madrid, 1972. 